\title{
Bakır/Gümüş Ara Tabaka Kullanılarak Difüzyon Kaynağıyla Birleştirilmiş AZ91 ve Al 2024 Alaşımının Mikroyapı ve Mekanik Özellikleri
}

\author{
Osman TORUN \\ Afyon Kocatepe Üniversitesi, Bolvadin Meslek Yüksekokulu, Afyonkarahisar, Türkiye \\ otorun@aku.edu.tr
}

Received/Geliș: 30.03.2018 Revised/Düzeltme: 02.05.2018 Accepted/Kabul: 02.05.2018

Öz: AZ91 Magnezyum alaşımı ve Al 2024 alüminyum alaşımı $440{ }^{\circ} \mathrm{C}$ 'de bakır/gümüş ara tabaka kullanılarak, $5 \mathrm{MPa}$ basınç ve $2.10^{-3} \mathrm{~Pa}$ vakum altında, 60, 90, 120 dakika sürelerde difüzyon kaynağ 1 yöntemiyle kaynaklanmıştır. Kaynaklanan numuneler birleşme yüzeyine dik olarak kesilmiştir, Kaynak bölgesi incelemeleri taramalı elektron mikroskobu (SEM) ile gerçekleştirilmiştir ve kaynak bölgesi EDS analizi yapılmıştır. Numunelere kesme testi uygulanmış ve kırılma yüzeyleri karakterize edilmiştir. Birleştirilen numunelerde kaynak bölgesi ve matriksin sertlikleri ölçülmüştür. Difüzyon bölgesinde sertlik değerleri arttığı belirlenmiş̧ir. Mikroyapı incelemelerinde boşluksuz ve sürekli bir difüzyon bölgesi gözlenmiştir. SEM-EDS analiz sonuçları, ara tabaka ve matris malzemeler arasında atom difüzyonunun olduğunu göstermiştir.

\section{Microstructure and Mechanical Properties of AZ91 and Al 2024 Alloys Joined with Diffusion Welding by Using Copper / Silver Interlayer}

\begin{abstract}
AZ91 Magnesium alloy and $\mathrm{Al} 2024$ aluminum alloy were welded at $440{ }^{\circ} \mathrm{C}$ for $60,90,120$ minutes under $5 \mathrm{MPa}$ pressure and $2.10^{-3} \mathrm{~Pa}$ vacuum using copper/silver interlayer by diffusion welding method. The welded samples were cut perpendicular to the joint surface. Welding zone examinations were performed by scanning electron microscopy and welding zone EDS analysis was done. Shear tests were applied to samples and the fractured surfaces were characterized. Hardness of the welded zone and matrix were measured on the joined samples. Hardness values increased in diffusion zone. Microstructure studies revealed a void-free and continuous diffusion zone. SEM-EDS analysis results showed that there was atom diffusion between the interlayer and the matrix materials.
\end{abstract}

Keywords: AZ91, AL2024, Diffusion welding, copper/siver interlayer

\section{Giriş}

$\mathrm{Mg}$ ve alaşımlarının uygulamaları özellikle otomobil, bilgisayar, iletişim alanında gün geçtikçe artmaktadır. Bu alaşımlar düşük yoğunluğa, boyutsal karalılığa, iyi işlenebilirliğe ve düşük döküm maliyetine sahiptir [1-4]. Al ve alaşımları yüksek mukavemet/ağırlık oranı ve mükemmel korozyon direncine sahip olması nedeniyle, özellikle otomobil sektörü, uzayhavacılık sektörü ve diğer endüstriyel uygulamalarda yapısal eleman olarak yaygın olarak kullanılmaktadır[5]. Mg ve Al alaşımlarının farklı malzemeler olarak ergitme kaynağıyla

Torun O., "Bakır/Gümüş Ara Tabaka Kullanılarak Difüzyon Kaynağıyla Birleştirilmiş AZ91 ve Al 2024 Alaşımının Mikroyapı ve Mekanik Özellikleri" El- Cezerî Fen ve Mühendislik Dergisi 2018, 5(2); 467-474. 
kaynağı özellikle oksit oluşumu, 1sıl çatlak oluşumu ve kırılgan intermetalik faz oluşumu nedeniyle oldukça zordur[6]. Difüzyon kaynağı; yüksek sıcaklıkta belirli bir basınç altında temas eden yüzeylerin birleştirilmesiyle meydana gelen bir katı hal kaynak işlemidir [7]. Bu kaynak işlemi çelikler, alüminyum alaşımları, titanyum alaşımları, nikel alaşımları, magnezyum alaşımları ve intermetalikler gibi birçok malzemede kullanılır. Difüzyon kaynağı iki karakteristik adımdan oluşur; birincisi yüzeylerin temasının sağlanması, ikincisi temas eden yüzeylerde metalik bağlanmanın tamamlanması. Sicaklık, süre, basınç, metalürjik etkiler, yüzey hazırlama ve ara tabaka kullanımı, difüzyon kaynağının kalitesini belirleyen en önemli parametrelerdir. Ara tabaka bağlanmayı olumsuz yönde etkileyecek metalürjik problemleri minimize etmek için kullanılır. Ara tabakalar toz, saçmalı ve buharlaştırma ile kaplama, elektrolizle kaplama ve folyo gibi birçok formda kullanılabilir [812].

Son zamanlarda farklı alüminyum ve magnezyum alaşımlarının ara tabakasız ve çeşitli ara tabakalar kullanılarak difüzyon kaynağı üzerine çok sayıda çalışma vardır [13-15]. Yapılan çalışmalarda, kaynak ara yüzeyleri incelenmiş ve kaynak bölgesinin mekanik özellikleri belirlenmeye çalışılmıştır. Bu çalışmada AZ91 magnezyum ve A12024 alüminyum alaşımı bakır/gümüş ara tabaka kullanılarak difüzyon kaynak yöntemiyle birleştirilmiştir. Kaynak bölgesi mikroyapı incelemeleri yapılmış ve mekanik özellikler belirlenmiştir.

\section{Materyal ve Metod}

AZ91 (Mg-9Al-1Zn) alaşımı atmosfer kontrollü firında argon gazı ortamında $750{ }^{\circ} \mathrm{C}$ 'de grafit potada ergitilmiş ve koruyucu gaz altında metal kalıba $10 \mathrm{~mm}$ çapında dökülmüştür. Al2024 (Al-4Cu-1.5Mg) alaşımı özel bir firmadan temin edilmiştir. Difüzyon kaynağı için numuneler $8 \mathrm{~mm}$ çapta ve $10 \mathrm{~mm}$ yükseklikte işlenmiştir. Daha sonra numuneler $1200 \mathrm{mesh}$ zımpara ile zımparalanmış ve $6 \mu \mathrm{m}$ 'lik pasta ile parlatılmış ve alkolle yüzeyler temizlenmiştir. A12024 alaşım numunelerin yüzeyleri elektroliz yöntemiyle yaklaşık $5 \mu \mathrm{m}$ civarında bakır ile kaplanmıştır. Ayrıca yaklaşık 20-30 $\mu \mathrm{m}$ kalınlıkta gümüş folyo ara tabaka hazırlanmış ve yüzeyi alkolle temizlenmiştir. Gümüş folyo ara tabaka olarak numunelerin arasına yerleştirilmiş (Şekil 1) ve kaynak işlemi, $440{ }^{\circ} \mathrm{C}$ 'de 60,90 ve 120 dakika sürelerde $5 \mathrm{MPa}$ yük ve $2.10^{-3} \mathrm{~Pa}$ vakum altında gerçekleștirilmiştir.

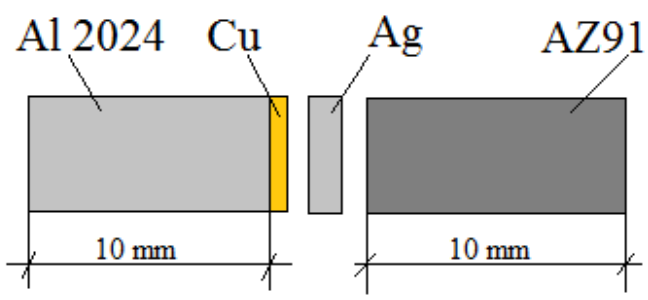

Şekil 1. Numune ve ara tabakaların şematik gösterimi.

Kaynak işlemi sonrası numuneler havada soğutulmuş ve herhangi bir işleme tabi tutulmamıştır. Her deney şartı için dört adet kaynak işlemi yapılmış, bu numunelerin üç âdeti kesme testi için, bir âdeti mikroyapı çalışmaları için kullanılmıştır. Mikroyapı çalışmaları için, kaynaklanmış numuneler kaynak ara yüzeyine dik olarak kesilmiş, 600 ve 1200 mesh' lik zımpara ile zımparalanmış ve $1 \mu \mathrm{m}$ ' lik elmas pasta ile parlatılmıştır. Kaynaklı numunelerin kaynak ara yüzeyleri ve kesme testine tabi tutulan numunelerin kırık yüzeyleri Taramalı Elektron Mikroskobunda incelenmiş ve kimyasal kompozisyonları enerji dağılım spektrometresi ile belirlenmiştir. Kaynaklı numunelerin kaynak bölgesinden her iki tarafa sertlik ölçümleri Vickers sertlik ölçme yöntemiyle, $50 \mathrm{~g}$ yük ve $15 \mathrm{~s}$ süre kullanılarak yapılmıştır. 


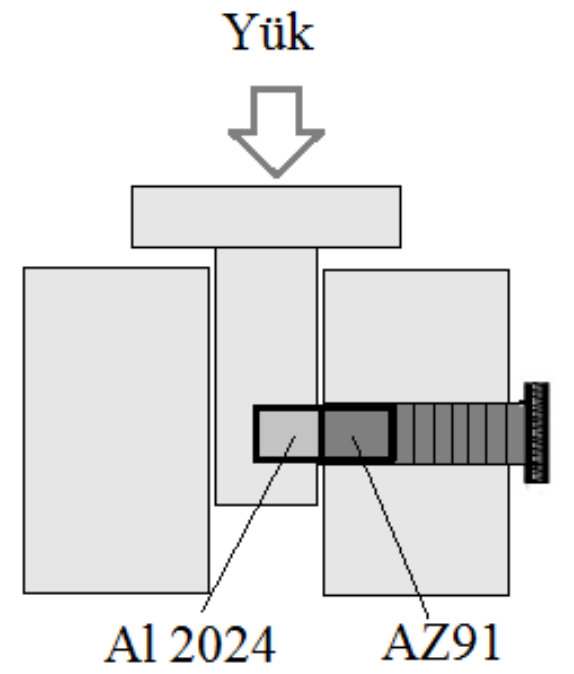

Şekil 2. Kesme testi aparatının şematik gösterimi.

Kesme mukavemetleri belirlemek için, numunelerin küçük boyutlarda olması nedeniyle özel olarak tasarlanmış ve Şekil 2' de gösterilen bir kesme testi aparatı kullanılmıştır. Kaynaklı numuneler kesme testi aparatına yerleştirilmiş ve $0,5 \mathrm{~mm} /$ dak. çene hızında kesme testine tabi tutulmuşlardır.

\section{Bulgular ve Tartışma}

Farklı sürelerde kaynaklanmış numunelerin kaynak ara yüzeyi mikroyapı incelemeleri ve kimyasal kompozisyon belirleme çalışmaları taramalı elektron mikroskobu ve enerji dağılım spektroskopisi kullanılarak gerçekleştirilmiştir. 60,90 ve 120 dakika sürelerde kaynaklanan numunelerin SEM mikroyapı fotoğrafı Şekil 3'te verilmektedir. Şekilden de görüldüğü gibi, AZ91 ve A12024 alaşımları arasında bütün süreler için boşluksuz, oksitsiz ve çatlaksız iyi bir birleşme olmuştur. Kaynak ara yüzeyinde bir difüzyon bölgesi oluştuğu şekilden açıkça görülmektedir. Difüzyon bölgesinde farklı tonlarda bölgeler vardır. Bu bölgelerden alınan analiz sonuçları Şekil 4'te gösterilmektedir. Analiz sonuçlarına göre bakır ve alüminyum atomları karşılıklı difüze olmuş, A ve B bölgelerini oluşturmuştur. A bölgesinde bakır ve alüminyum atomlarının miktarları yaklaşık olarak aynıdır. B bölgesi bakırca daha zengin bir fazdır, alüminyum miktarı ağ.\%15 civarındadır. B bölgesinde gümüş atomları da tespit edilmiş ve yaklaşık ağ.\% 1,58 ölçülmüştür.

$\mathrm{Bu}$ sonuçlar deney koşullarında, bakır-gümüş arasındaki difüzyonun, bakır-alüminyum arasındaki difüzyona göre daha yavaş olduğunu göstermektedir. C bölgesi ara tabaka olan gümüştür. D ve E bölgesi magnezyum ve gümüş atomlarının karş1lıklı difüzyonu ile oluşan bölgelerdir. Magnezyum atomları gümüş difüze olmuş ve $\mathrm{D}$ bölgesinde yaklaşık olarak ağ.\%11,5 ölçülmüştür. E bölgesinde gümüş atomlarının miktarı azalırken, $\mathrm{Mg}$ atomlarının miktarı ağ. \%30 kadar artmıştır. 90 ve 120 dakika sürede kaynaklanan numunelerin analiz sonuçları, 60 dakikada kaynaklanan numunelerle benzer olduğu görülmüştür. Süredeki artış atomların difüzyonunu arttırmış, 90 ve 120 dakika sürede $\mathrm{C}$ ve $\mathrm{D}$ difüzyon bölgelerinin genişlemesine neden olmuştur. 


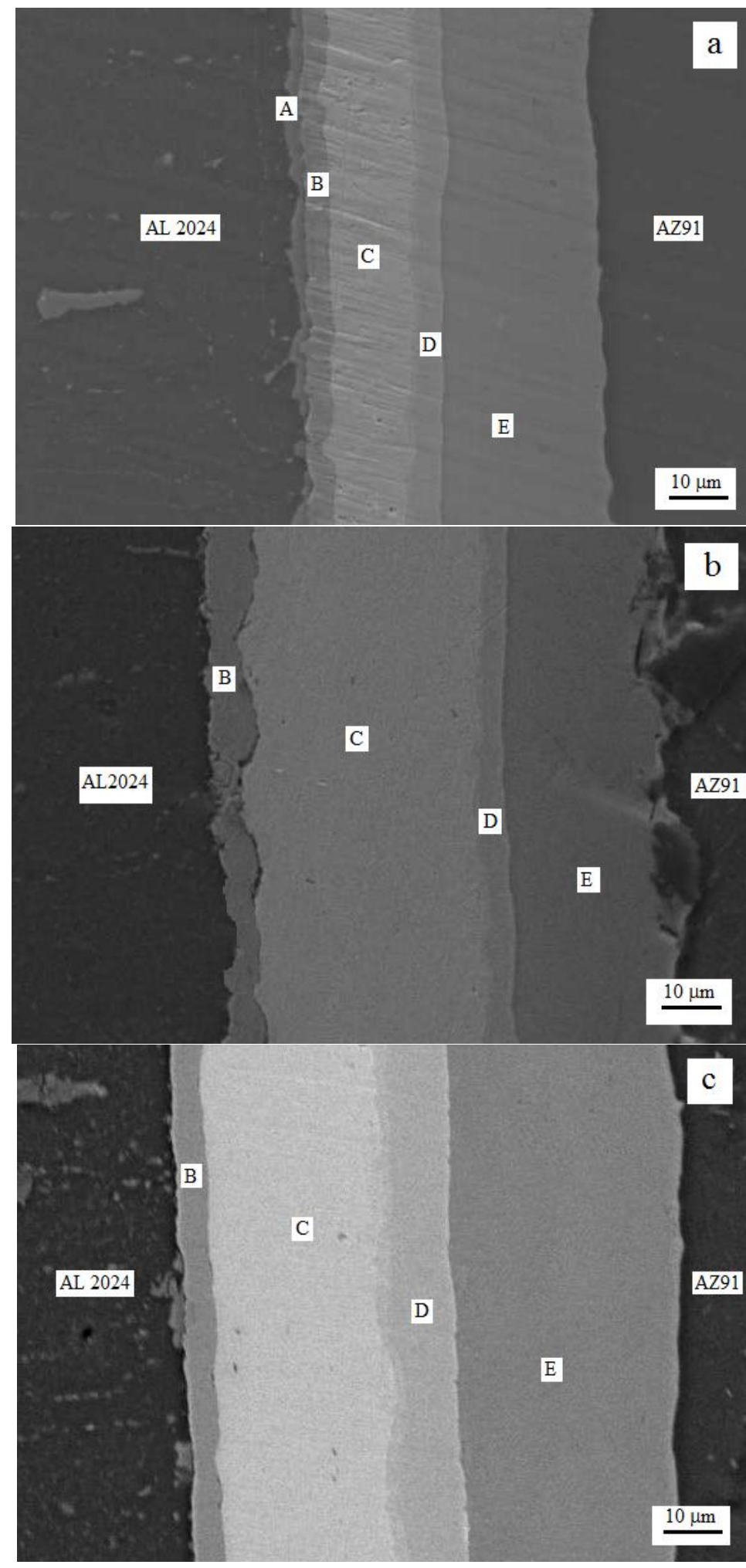

Şekil 3. 6090 ve 120 dakika sürede kaynak yapılan numunelerin taramalı elektron mikroskop görüntüsü. a) 60 dak. b) 90 dak. c) 120 dak. 


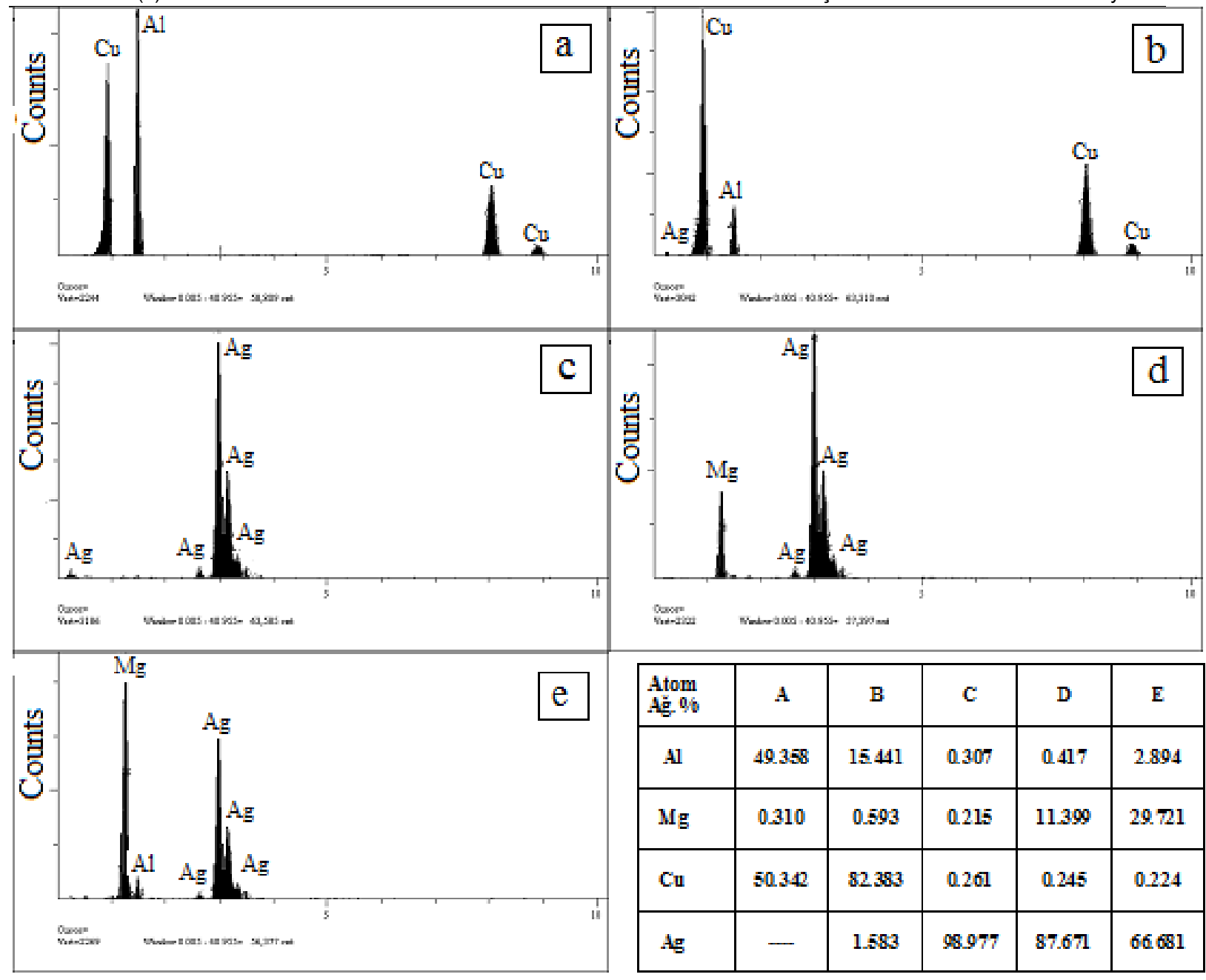

Şekil 4. 60 dakika sürede kaynaklanan numunede A, B, C, D, E noktalarının EDS analizleri. a) A noktas1 b) B noktasi c) C noktasi d) D noktas1 e) E noktas1.

Kaynaklı numunelerin mikrosertlik değerleri Şekil 5'te verilmektedir. Şekilden de görüldüğü gibi tüm süreler için sertlik dağılımları benzerdir. Ara tabaka sertliği yaklaşık 75 Hv olarak ölçülürken, difüzyon bölgelerinde oluşan farklı fazlar nedeniyle sertlikler artmıştır. AZ91 alaşımı tarafında gümüş atomlarının AZ91 alaşımına difüzyonu, difüzyon bölgesine bitişik bölgede sertliği hayli artmasına neden olmuştur. Şekil 6'da kaynak bölgesi mukavemet değerleri gösterilmiştir. Mukavemet değerlerinde belirli bir eğilim yoktur.

Tüm kaynak süreleri için mukavemet değerleri birbirine oldukça yakındır. Mikroyapı fotoğrafından da görüldüğü gibi 60 dakika kaynak süresinde oluşan difüzyon bölgesi ara yüzey fazları, diğer sürelerde kaynaklanan numunelerde oluşan fazlarla benzerdir. Dolayısıyla, kesme testi esnasında kopmaların aynı faz bölgelerinden gerçekleştiği düşünülmektedir. En yüksek mukavemet değeri 12,3 MPa olarak 120 dakika sürede kaynak yapılmış numune elde edilmiştir. 


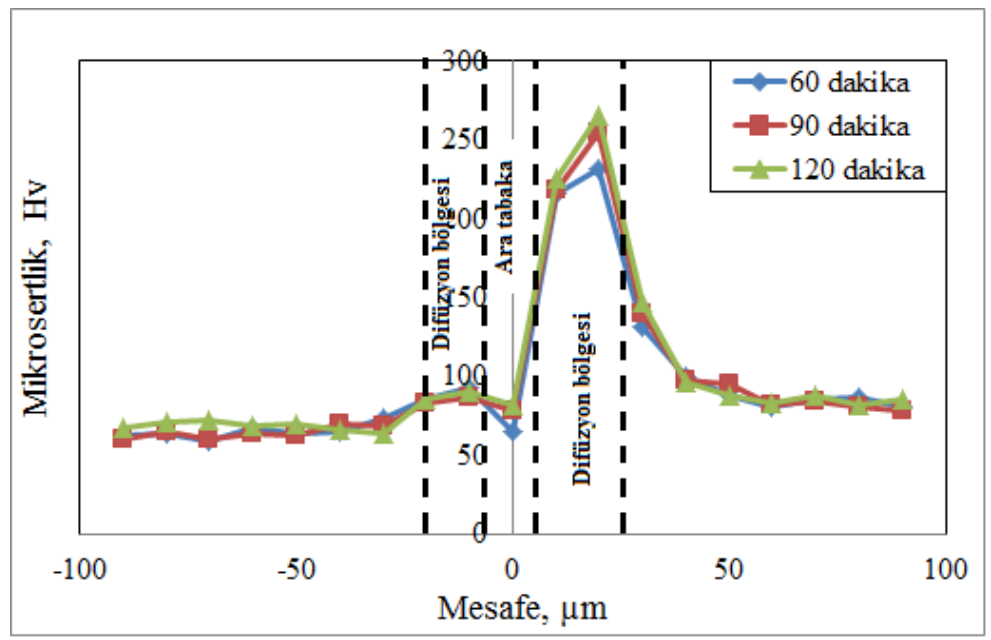

Şekil 5. Kaynaklı numunelerin merkezden her iki tarafa sertlik değerleri.

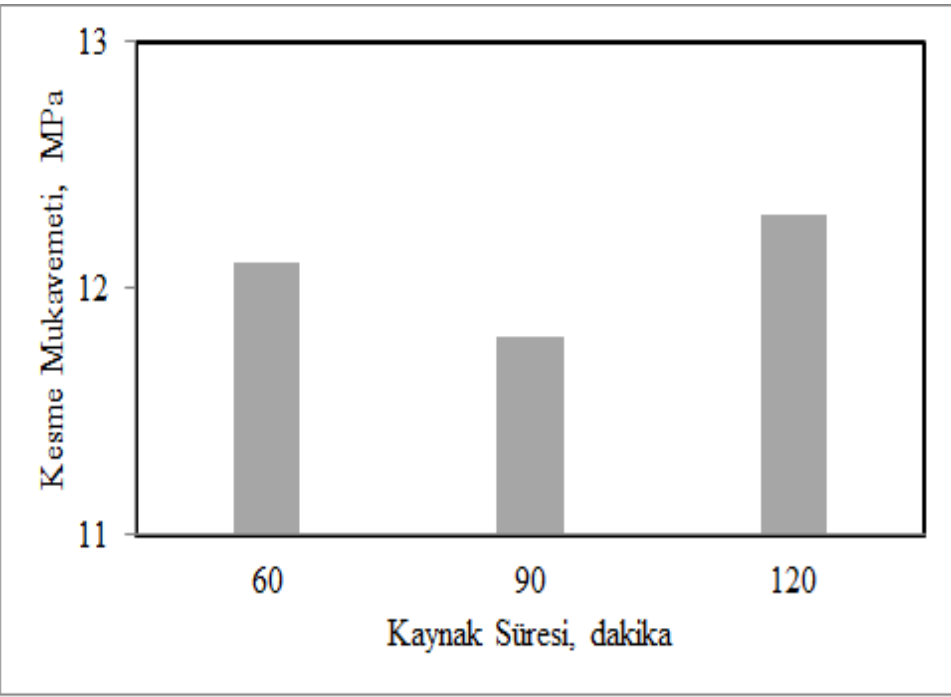

Şekil 6. Kaynaklı numunelerin kesme mukavemeti değerleri

60 dakika süre kaynak yapılan numunenin kesme testi sonrasında, AZ91 alaşımı tarafı ve A12024 alaşımı tarafından çekilen taramalı elektron mikroskop fotoğrafları Şekil 7 ' de gösterilmektedir. Yüzeylerden alınan EDS analizleri, her iki yüzeyde de Ag-Mg-Al atomlarının benzer oranlarda varlığını göstermektedir. Bulgular kaynak ara yüzeyindeki gümüş ara tabaka ile AZ91 alaşımı arasında oluşan difüzyon bölgesindeki EDS sonuçları ile benzerlik göstermektedir. Bu durum, kesme esnasında kopmaların AZ91 alaşımına bitişik difüzyon bölgesinden olduğunu göstermektedir 

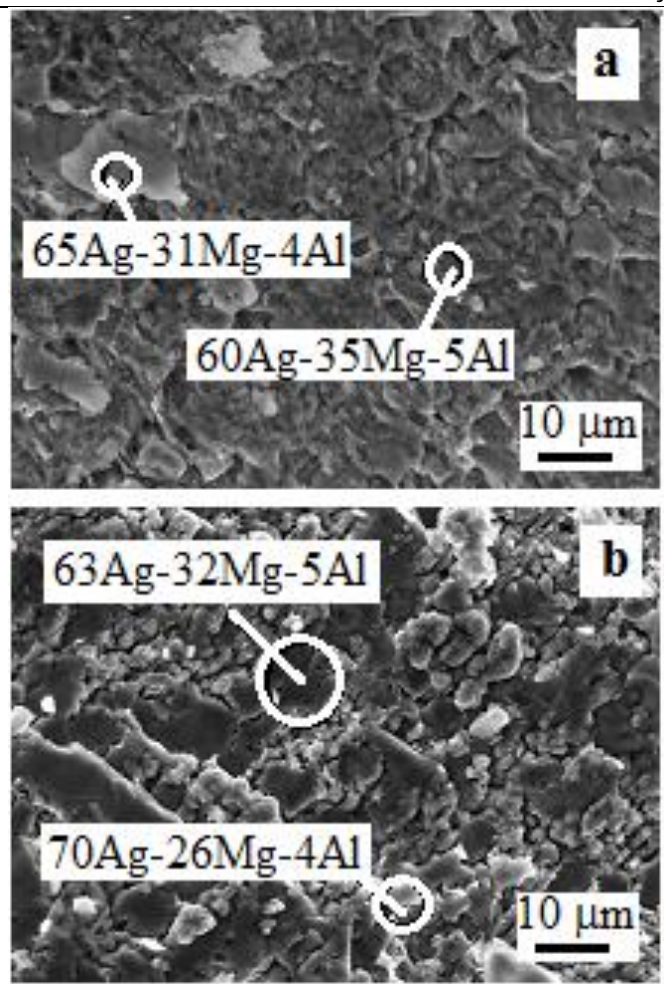

Şekil 7. 60 dakika sürede kaynak yapılan numunenin taramalı elektron mikroskop görüntüsü. a) AZ91 tarafı b) Al 2024 tarafı

\section{Sonuçlar}

AZ91 ve A12024 alaşımı bakır/gümüş ara tabaka kullanılarak 60, 90, 120 dakika sürelerde 5 $\mathrm{MPa}$ basınç ve $2.10^{-3} \mathrm{~Pa}$ vakum altında difüzyon kaynağı ile başarılı bir şekilde birleştirilmiştir. A12024 alaşımı yüzeyine kaplanan bakır, alaşımın yüzeyinde oluşacak oksit tabakası oluşumunu engellemiştir. Kaynak arayüzeyinde A12024 ve AZ91alaşımı tarafinda farklı fazlardan oluşan difüzyon bölgeleri gözlenmiştir. Deney şartlarında kaynak kesme mukavemeti kaynak süresinden bağımsızdır. Ara yüzeyde intermetalik fazların oluşması nedeniyle, düşük kesme mukavemetleri gözlenmiştir ve en yüksek kesme mukavemeti 12,3 MPa olarak, elde edilmiştir.

\section{Teşekkür}

Bu çalışma, Afyon Kocatepe Üniversitesi, Bilimsel Araştırma Projeleri Koordinasyon birimi tarafından 14.MYO.02 nolu proje ile desteklenmiştir.

\section{Kaynaklar}

[1] Zhang J., Luo G., Wang Y., Shen Q., Zhang L., "An investigation on diffusion bonding of aluminum and magnesium using a Ni interlayer", Materials Letters, 83 (2012) 189191.

[2] Joseph F. M., Senthilkumar T., Balasubramanian V., "Developing Temperature-Time and Pressure-Time Diagrams for Diffusion Bonding AZ31B Magnesium and AA6061 Aluminium Alloys", Trans Indian Inst Met, 2013, 66 (2), 177-183. 
[3] Li X.R., Liang W., Zhao X.G., Zhang Y., Fu X.P., Liu F.C., "Bonding of Mg and Al with $\mathrm{Mg}-\mathrm{Al}$ eutectic alloy and its application in aluminum coating on magnesium", $\mathrm{J}$ Alloy Compd., 2009, 471, 408-411.

[4] Choi D., Ahn B., Lee C., Yeon Y., Song K., Jung S., "Formation of intermetallic compounds in $\mathrm{Al}$ and $\mathrm{Mg}$ alloy interface during friction stir spot welding", Intermetallics, 2011, 19, 125-130.

[5] Eslami P, Taheri A.K., "An investigation on diffusion bonding of aluminum to copper using equal channel angular extrusion process", Mater Lett., 2011, 65, 1862-1867.

[6] Balasubramanian V., Joseph F. M., Senthilkumar T., "Development of processing windows for diffusion bonding of aluminum/magnesium dissimilar materials" Weld World, 2013, 57, 523-539.

[7] Owczarski W.A., Gerken J., Gripshowe P., Metcalfe A.G., Schwartz M.M., In: Griffing L, editor. Welding handbook section 3B. 6th ed. USA: American Welding Society; 5, (1971).

[8] Somekawa H., Hosokawa H., Watanable H., Higashi K., , Diffusion bonding in superplastic magnesium alloys., Mater Sci Eng A, 2003, 339, 328-333.

[9] Ghosh M., Chatterjee S., "Effect of interface microstructure on the bond strength of the diffusion welded joints between titanium and stainless steel”, Mater Charact, 2005, 54, 327-337.

[10] He P., Feng J.C., Zhang B.G., Qian Y.Y., "Microstructure and strength of diffusion bonded joints of TiAl base alloy to steel", Mater Charact, 2002, 48, 401-406.

[11] Ling P., David E. L., "A study on diffusion couples of Ti and polysynthetically twinned (PST) Ti-Al: I. Microstructure characterization”, Intermetallics, 2006, 14, 6167.

[12] Torun O., Çelikyürek I., "Diffusion bonding of nickel aluminide Ni75A125 using a pure nickel interlayer", Intermetallics, 2008, 16, 406-409.

[13] Liu W., Long L., Ma Y., Wu L., "Microstructure evolution and mechanical properties of $\mathrm{Mg} / \mathrm{Al}$ diffusion bonded joints", Journal of Alloys and Compounds, 2015, 643, 3435 .

[14] Jafarian M., Khodabandeh A., Manafi S., , "Evaluation of diffusion welding of 6061 aluminum and AZ31 magnesium alloys without using an interlayer", Materials and Design, 2015, 65, 160-164.

[15] Zhang J., Qiang L. G., Qiang S., Zhang L.-M., Huang Z. J., "Characterization of diffusion- bonded joint between $\mathrm{Al}$ and $\mathrm{Mg}$ using a Ni interlayer", Rare Metals. (2014) DOI 10.1007/s12598-014-0394-0. 